\title{
Effect of the Family Food Environment and Dietary Behaviors on Obese Children and Adolescents
}

\author{
Abdulmoein Eid Al-Agha* and Nouf Mohammed AL-Nosani
}

King Abdulaziz University, Jeddah, Saudi Arabia

\begin{abstract}
Introduction: The prevalence of overweight and obesity among the children are increasing in the last two decades in Kingdom of Saudi Arabia. However, there are limited studies regarding dietary behaviour on children and adolescents with obesity.

Materials and methods: A cross-sectional study data collected over six months August 2014-February 2015 Sample size was 293 children and adolescents (4-16 years old age) randomly selected from the ambulatory clinic in King Abdulaziz University Hospital. Data analysed by using statistical package for social science (SPSS), version 16.

Results: There was a significant relation between eating outside the home and Body Mass Index and ratio of center circumference to hip, $(p=0.018)$. The data shows that children who eat while they watch television have higher Body Mass Index score than who were not $(p=0.036) r=0.143$. Moreover, there were also association of children dietary behaviour and Body Mass Index scores of children. Children who drink soft drinks ( $p=0,023$, $r=0,141)$ and not doing exercises $(p=0,01, r=0,347$ and $p=0.008, r=-0.167$ have high Body Mass Index respectively). On the other hand, we found that kids who eat with their families have lower weight while height was controlled $(p=0.012, r=-0.335)$.

Conclusion and recommendations: Findings, along with the results of the present study, suggest that the availability of obesity-promoting foods in an adolescent's home and eating behaviour promotes the consumption of these foods/fluids and increase the risk of obesity for both sexes. Therefore we recommended that to regulate the availability of unhealthy food/fluids may reduce adolescent BMI change as well we advise to decrease fast food and soft drinks consumption.
\end{abstract}

Keywords: Obesity in children and adolescents; Poor quality food environments; Unhealthy eating behaviors; Eating in front of the television; Eating with family; Body mass index; Exercise

\section{Introduction}

Obesity in children and adolescents is one of the most widespread medical problems worldwide, including in the Kingdom of Saudi Arabia (KSA). Evidence shows that the prevalence of overweight and obesity among children has increased in the last two decades in the KSA. A Saudi study reported that the prevalence of overweight and obesity among primary and intermediate school students is $11 \%$ and $15.9 \%$, respectively [1]. A notable public health problem is the consumption of fast food and soft drinks by children and adolescents, which is correlated with a higher risk of obesity [2]. Increased opportunities for energy intake accompanied with limited energy expenditure are the most important factors underlying the high prevalence of obesity in children and adolescents, accordingly to a community-based national epidemiological health study in Saudi Arabia, which reported that the prevalence of overweight and obesity are $36.9 \%$ and $35.5 \%$, respectively $[3,4]$. Obese children and adolescents are more likely to be obese adults, which leads to health problems that contribute to significant morbidity and mortality $[5,6]$. As there are limited studies regarding dietary behavior in obese children and adolescents in KSA, the aim of the current study was to determine the effect of family food environment and dietary behaviors on obese children and adolescents living in Jeddah, Saudi Arabia.

\section{Methods}

This was a cross-sectional study conducted in young girls and boys. Participants were recruited from the ambulatory clinic of King Abdulaziz Hospital from August 2014 to February 2015. The study population consisted of 293 children and adolescents aged 4-16 years who were there to check their anthropometric measures for the healthy child checkup clinic. Data were obtained from a questionnaire with a series of multiple choice questions depends primarily upon the method closed ended questions. Informed verbal consent was obtained from the participants or their parents, ethical approval taken from King Abdulaziz University ethical committee. Data comprised participants' socio demographic variables, medical history, dietary history, anthropometric measurements, use of a dietary intervention, use of hormonal treatment, and the presence of endocrinopathy, leading to the development of secondary sexual character and serious illness. The exclusion criteria were child on dietary intervention, exposure to hormone treatment, development of secondary obesity due to endocrinopathy, serious intercurrent illness and data insufficiency due to incomplete questionnaires were excluded. All participants were divided into three groups according to their body mass index (BMI): normal weight (BMI between the fifth and eighty-fifth percentiles), overweight (BMI between the eighty-fifth and ninety-fifth percentiles), obesity BMI (more than the ninety-fifth percentile), and severe obesity (BMI more than the ninety-ninth percentile). Weight was

*Corresponding author: Abdulmoein Eid Al-Agha, King Abdulaziz University Jeddah, Saudi Arabia, Tel: 00966505590459; E-mail: aagha@kau.edu.sa

Received March 11, 2016; Accepted March 26, 2016; Published March 31, 2016

Citation: Al-Agha AE, AL-Nosani NM (2016) Effect of the Family Food Environment and Dietary Behaviors on Obese Children and Adolescents. J Diabetes Metab 7: 661. doi:10.4172/2155-6156.1000661

Copyright: (c) $2016 \mathrm{Al}-\mathrm{Agha} \mathrm{AE}$, et al. This is an open-access article distributed under the terms of the Creative Commons Attribution License, which permits unrestricted use, distribution, and reproduction in any medium, provided the original author and source are credited. 
measured with participants in light clothing and their shoes off. BMI was calculated as weight $(\mathrm{kg})$ divided by height squared $\left(\mathrm{m}^{2}\right)$. The BMI percentile was determined for each participant according to the Centers for Disease Control and Prevention's growth charts [7]. We analyzed the following items: personal data and home food availability, which is comprised of two factors in a general survey. One factor labeled as unhealthy food availability was described as the availability of chips, sweets, and soft drinks in the home, which are identified as major contributors to energy, fat, and high caloric intake. The other factor was healthy and general food availability, which was described as the availability of vegetables and fruits in the home. The formality of eating was assessing according to the degree of the formality used when preparing and consuming meals (e.g. whether meals were eaten with the television on or with family, and whether meals started with salads). We also assessed the type of food and drinks that the participants liked and disliked. The included items were chips, sweets, soft drinks, carbohydrates, vegetables and fruit. The use of a questionnaire can influence results forced-choice format, generally speaking, carry out a qualitative research to probe of the population about some sociology issues and then used to test about certain medical conditions and health practice. The results of these studies differ according to the literacy, residence, economic standards, and level of education. So, the generalization of these studies is difficult, and the usefulness of such studies are restricted to apply a health education program. These types of studies are also useful to compare before and after application of an intervention program.

\section{Statistical analysis}

Data were entered, coded, and analyzed using the Statistical Package for Social Science, version 16 (SPSS, Inc., Chicago, IL). We performed the analyses by determining the correlation coefficients and testing the significance of relationships between dietary behaviors and body measurements (i.e. the BMI and ratio of center circumference to hip) using point biserial correlation and Pearson's correlation (in special cases) after we assumed that the data followed a normal distribution. Results were considered significant at $\mathrm{p}<0.05$ and sometimes $\mathrm{p}<0.01$. The chi-square test was used to calculate the statistical significance among BMI categories (depending on the BMI SDS scores) and dietary behaviors. Also, a partial correlation was used to analyze the association with weight in $\mathrm{kg}$ while height in centimeters was controlled.

\section{Results}

The study included 293 children and adolescents (mean age: 10.8 \pm 4.1 years; $53.6 \%$ boys, $46.4 \%$ girls). Twenty-five (11.7\%) participants were overweight, $92(43.2 \%)$ were obese, and 88 (41.3\%) were severely obese. Children and adolescents who ate vegetables and fruits had a lower ratio of waist circumference to hip than those who did not eat vegetables and fruits $(\mathrm{p}=0.05, \mathrm{r}=-0.130)$. One hundred eightyeight $(78.7 \%)$ preferred to eat vegetables and fruits, and $51(21.3 \%)$ did not prefer vegetables and fruits. Eating fast food had a significant correlation with BMI and the ration of waist circumference to hip $(p=0.018)$. Fast food was a popular type of food that children and adolescents ate outside of the home, and children who preferred to eat fast food had a higher BMI score than those who did not prefer to eat fast food ( $\mathrm{p}=0.041 ; \mathrm{r}=0.163$ and $\mathrm{r}=0.145$, respectively). Of them, 71 (40.1\%) were obese and 67 (37.9\%) were severely obese (Figure 1). One hundred thirty-five (90\%) participants preferred to drink soft drinks and had a higher BMI score as a consequence of preferring soft drinks $(\mathrm{p}=0.023, \mathrm{r}=0.141)$.

Providing healthy food (e.g., salads, vegetables, and fruits) at home is an important factor that can affect body measurements, and we found a significant relationship between starting meals with a salad and the BMI scores; children who did not start their meals with a salad had higher BMI scores than those who started their meals with a salad ( $\mathrm{p}=$ 0.035). Of them, $61(29.6 \%)$ were obese, and 52 (25.2\%) were severely obese (Figure 2). Eating in front of the television was considered a risk factor of obesity. Children and adolescents who ate while watching television had a higher BMI score than those who did not eat while watching television $(p=0.036, r=0.143)$. Eating with family is another important factor, and our results showed that children and adolescents who ate with their families had a lower weight, while their height was controlled $(\mathrm{p}=0.012, \mathrm{r}=-0.335)$. Exercise is also an important factor that can effect body measurements; children and adolescents who did

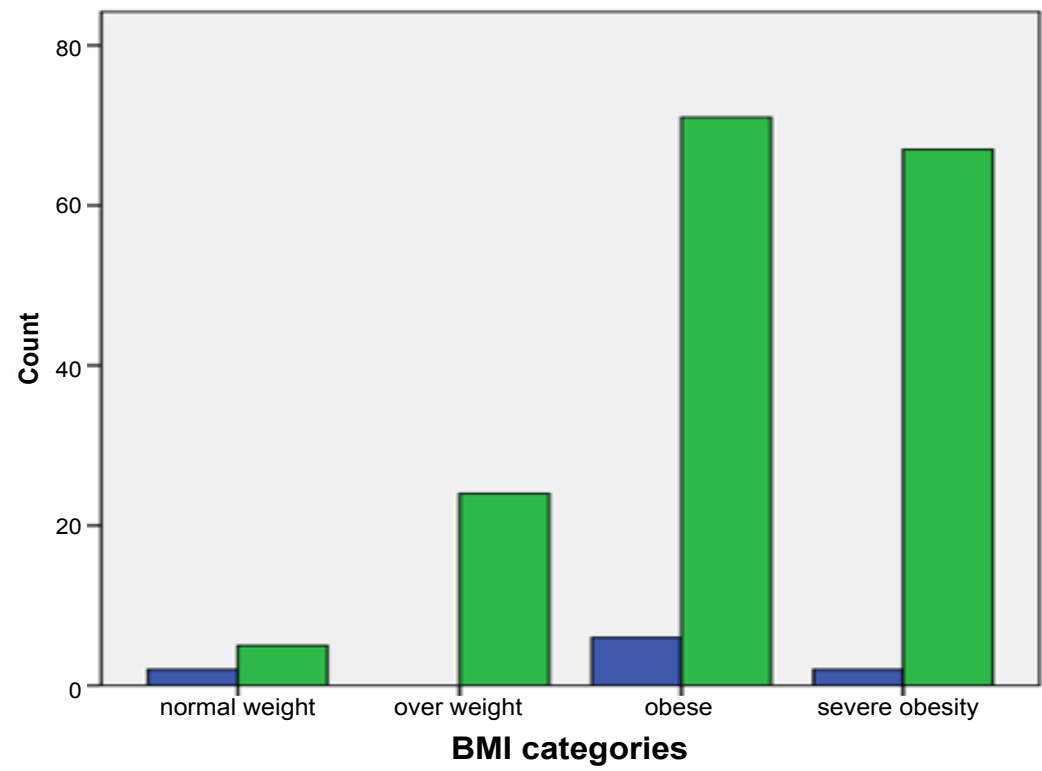

Figure 1: Bar chart showing the preference for fast food and body mass index (BMI) categories among the participants. 


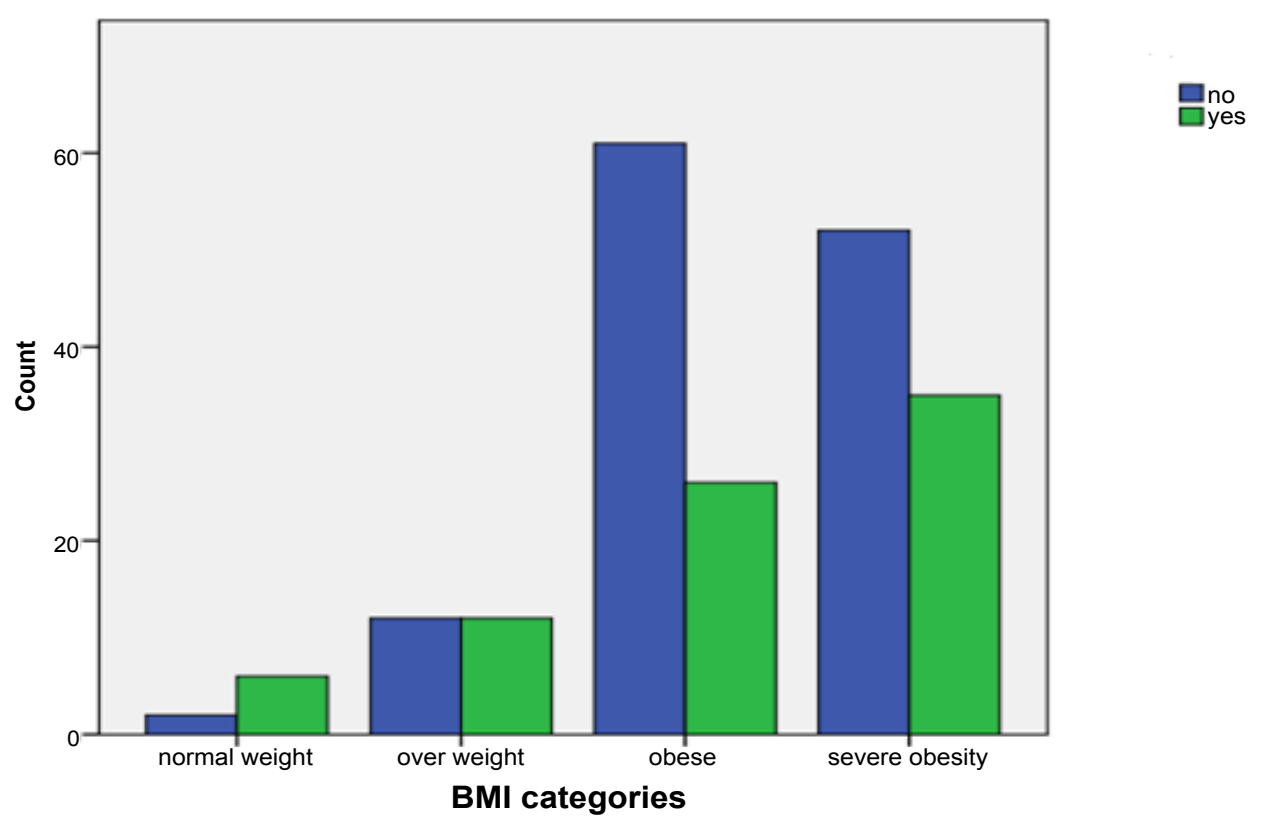

Figure 2: Bar chart showing participants who started their meals with a salad and the body mass index (BMI) categories.

\begin{tabular}{|c|c|c|c|c|c|c|c|}
\hline & & & \multicolumn{4}{|c|}{ BMIcategories } & \multirow{2}{*}{ Total } \\
\hline & & & normal weight & overweight & obese & severe obesity & \\
\hline \multirow{6}{*}{ unhealthyYes } & \multirow{3}{*}{ no } & Count & 0 & 0 & 5 & 9 & 14 \\
\hline & & Expected Count & .5 & 1.7 & 5.9 & 5.8 & 14.0 \\
\hline & & $\%$ of Total & $.0 \%$ & $.0 \%$ & $2.4 \%$ & $4.4 \%$ & $6.8 \%$ \\
\hline & \multirow{3}{*}{ yes } & Count & 8 & 25 & 82 & 76 & 191 \\
\hline & & Expected Count & 7.5 & 23.3 & 81.1 & 79.2 & 191.0 \\
\hline & & $\%$ of Total & $3.9 \%$ & $12.2 \%$ & $40.0 \%$ & $37.1 \%$ & $93.2 \%$ \\
\hline \multirow[t]{3}{*}{ Total } & & Count & 8 & 25 & 87 & 85 & 205 \\
\hline & & Expected Count & 8.0 & 25.0 & 87.0 & 85.0 & 205.0 \\
\hline & & $\%$ of Total & $3.9 \%$ & $12.2 \%$ & $42.4 \%$ & $41.5 \%$ & $100.0 \%$ \\
\hline
\end{tabular}

Table 1: Crosstab of the study population.

not exercise for $\geq 30 \mathrm{~min}$ had a higher weight while their height was controlled, and they had a higher ratio score $(\mathrm{p}=0.01, \mathrm{r}=0.347$; and $\mathrm{p}$ $=0.008, \mathrm{r}=-0.167$, respectively. Additionally, exercise for $\geq 30 \mathrm{~min}$ had a significant association with the ratio of center circumference to hip ( $\mathrm{p}$ $=0.008<0.01, \mathrm{r}=-0.167)$ (Tables 1-3).

\section{Discussion}

The present study is unique in its description of associations between the aspects of an adolescent's home food environment and dietary behaviors, which likely promote overweight and obesity in adolescence. A previous literature review was conducted and confirmed a positive relationship among obesity, diet composition, and eating behaviors [8]. One of the main factors contributing to an increase body weight is the imbalance between calorie intake, energy expenditure, and eating behaviors, including not eating at home and consuming large or excessive calories by soft drinks, snacks, and large portions [9]. Children's dietary habits have shifted away from healthy foods such as vegetables, fruits, and whole grains to fast food, processed snack foods, and carbonated soft drinks instead of water. These foods and drinks have a high fat intake and/or calories, and they are low in nutrients, especially vitamins and fibers, recently natural products such as or dietary phytochemicals such as carotenoids (crocin), glycoside (picrocrocin) and a volatile oil component (safranal) have hoard much interest as agents to counter obesity. These compounds regulating lipid absorption by the anti-obesity properties, decrease lipogenesis, increase lipolysis, and differentiate the proliferation of pre-adipocytes in addition antigenotoxic, cytotoxic effects and antioxidant [10]. Eating too many snacks disrupts the physiological rhythm of the digestive system due to large amounts of sugars, carbohydrates, and lipids [11]. In our study, there was a significant association between eating a salad and the BMI SDS categories. Children and adolescents who did not eat salads had a higher weight than those who did eat salad. In addition, children and adolescents who ate vegetables and fruits had a lower ratio of waist circumference to hip ratio than those who did not eat vegetables and fruits. Eating at fast food restaurants is a major cause of obesity. For instance, an increased supply of fast food can account for $0.5 \%$ of the increase in obesity over the last 30 years among California's public schools ninth graders [2]. There is considerable evidence in the epidemiological literature regarding the correlation between fast food consumption and obesity; likewise, we found that eating fast food was significantly correlated with the BMI and waist circumference to hip ratio in our study. Children and adolescents who preferred to eat fast food had a higher BMI score than those who did not prefer to eat fast food.

A 2014 case-control study conducted by Martin-Calvo et al. [12] in Spain evaluated the association between the consumption of sugar- 
Citation: Al-Agha AE, AL-Nosani NM (2016) Effect of the Family Food Environment and Dietary Behaviors on Obese Children and Adolescents. J Diabetes Metab 7: 661. doi:10.4172/2155-6156.1000661

Page 4 of 5

\begin{tabular}{|c|c|c|c|c|c|c|c|}
\hline & & $\mathrm{BMI}$ in $\mathbf{k g l m ^ { 2 }}$ & BMI in sds & $\begin{array}{l}\text { Ratio of center } \\
\text { Circumference } \\
\text { to hip }\end{array}$ & EatingTvNO & EatingTYES & $\begin{array}{c}\text { Eating } \\
\text { Tv } \\
\text { SOMETIMES }\end{array}$ \\
\hline \multirow[t]{3}{*}{$\mathrm{BMI}$ in $\mathrm{kglm}{ }^{2}$} & Pearson Correlation & 1 & $.473^{* *}$ & 0.025 & $-.041-$ & 0.109 & $-.026-$ \\
\hline & \multicolumn{2}{|c|}{ Sig. (2-tailed) } & 0 & 0.687 & 0.495 & 0.071 & 0.667 \\
\hline & $\mathrm{N}$ & 276 & 210 & 257 & 276 & 276 & 276 \\
\hline \multirow[t]{3}{*}{$\mathrm{BMI}$ in sds } & Pearson Correlation & $.473^{* *}$ & 1 & $.273^{* *}$ & $-.098-$ & $.143^{*}$ & $-.050-$ \\
\hline & Sig. (2-tailed) & 0 & & 0 & 0.152 & 0.036 & 0.472 \\
\hline & $\mathrm{N}$ & 210 & 213 & 203 & 213 & 213 & 213 \\
\hline \multirow[t]{3}{*}{$\begin{array}{c}\text { Ratio of center } \\
\text { Circumference to hip }\end{array}$} & Pearson Correlation & 0.025 & $.273^{* *}$ & 1 & $-.046-$ & $-.007-$ & 0.042 \\
\hline & Sig. (2-tailed) & 0.687 & 0 & & 0.454 & 0.911 & 0.496 \\
\hline & $\mathrm{N}$ & 257 & 203 & 266 & 266 & 266 & 266 \\
\hline \multirow[t]{3}{*}{ EatingTvNO } & Pearson Correlation & $-.041-$ & $-.098-$ & $-.046-$ & 1 & $-.461^{* *}$ & $-.216^{* *}$ \\
\hline & Sig. (2-tailed) & 0.495 & 0.152 & 0.454 & & 0 & 0 \\
\hline & $\mathrm{N}$ & 276 & 213 & 266 & 293 & 293 & 293 \\
\hline \multirow[t]{3}{*}{ Eating TYES } & Pearson Correlation & 0.109 & $.143^{*}$ & $-.007-$ & $-.461^{* *}$ & 1 & $-.596^{* *}$ \\
\hline & Sig. (2-tailed) & 0.071 & 0.036 & 0.911 & 0 & & 0 \\
\hline & $\mathrm{N}$ & 276 & 213 & 266 & 293 & 293 & 293 \\
\hline \multirow[t]{3}{*}{ EatingTvSOMETIMES } & Pearson Correlation & $-.026-$ & $-.050-$ & 0.042 & $-.216^{\star *}$ & $-.596^{\star *}$ & 1 \\
\hline & Sig. (2-tailed) & 0.667 & 0.472 & 0.496 & 0 & 0 & \\
\hline & $\mathrm{N}$ & 276 & 213 & 266 & 293 & 293 & 293 \\
\hline
\end{tabular}

Table 2: Correlations.

\begin{tabular}{|c|c|c|c|c|c|c|c|}
\hline & & $\mathrm{BMI}$ in $\mathbf{k g l m ^ { 2 }}$ & BMI in sds & $\begin{array}{l}\text { Ratio of center } \\
\text { Circumference } \\
\text { to hip }\end{array}$ & $\begin{array}{l}\text { no eating } \\
\text { outside }\end{array}$ & $\begin{array}{l}\text { yes eating } \\
\text { outside }\end{array}$ & $\begin{array}{l}\text { sometimes } \\
\text { eating outside }\end{array}$ \\
\hline \multirow{3}{*}{$\mathrm{BMI}$ in $\mathrm{kglm}{ }^{2}$} & Pearson Correlation & 1 & $.473^{* *}$ & 0.025 & $-.068-$ & $-.021-$ & 0.094 \\
\hline & Sig. (2-tailed) & & 0 & 0.687 & 0.26 & 0.734 & 0.118 \\
\hline & $\mathrm{N}$ & 276 & 210 & 257 & 276 & 276 & 276 \\
\hline \multirow{3}{*}{ BMI in sds } & Pearson Correlation & $.473^{* *}$ & 1 & $.273^{\star *}$ & $-.094-$ & $.163^{*}$ & $-.084-$ \\
\hline & Sig. (2-tailed) & 0 & & 0 & 0.169 & 0.018 & 0.224 \\
\hline & $\mathrm{N}$ & 210 & 213 & 203 & 213 & 213 & 213 \\
\hline \multirow{3}{*}{$\begin{array}{c}\text { Ratio of center } \\
\text { Circumference to hip }\end{array}$} & Pearson Correlation & 0.025 & $.273^{* *}$ & 1 & $-.052-$ & $.145^{*}$ & $-.087-$ \\
\hline & Sig. (2-tailed) & 0.687 & 0 & & 0.401 & 0.018 & 0.155 \\
\hline & $\mathrm{N}$ & 257 & 203 & 266 & 266 & 266 & 266 \\
\hline \multirow{3}{*}{ no eating outside } & Pearson Correlation & $-.068-$ & $-.094-$ & $-.052-$ & 1 & $-.273^{* *}$ & $-.399^{* *}$ \\
\hline & Sig. (2-tailed) & 0.26 & 0.169 & 0.401 & & 0 & 0 \\
\hline & $\mathrm{N}$ & 276 & 213 & 266 & 293 & 293 & 293 \\
\hline \multirow{3}{*}{ yes eating outside } & Pearson Correlation & $-.021-$ & $.163^{*}$ & $.145^{\star}$ & $-.273^{* *}$ & 1 & $-.670^{* *}$ \\
\hline & Sig. (2-tailed) & 0.734 & 0.018 & 0.018 & 0 & & 0 \\
\hline & $\mathrm{N}$ & 276 & 213 & 266 & 293 & 293 & 293 \\
\hline \multirow{3}{*}{ sometimes eating outside } & Pearson Correlation & 0.094 & $-.084-$ & $-.087-$ & $-.399^{* *}$ & $-.670^{* *}$ & 1 \\
\hline & Sig. (2-tailed) & 0.118 & 0.224 & 0.155 & 0 & 0 & \\
\hline & $\mathrm{N}$ & 276 & 213 & 266 & 293 & 293 & 293 \\
\hline
\end{tabular}

Table 3: Eating outside with BMI and ratio: Correlations.

sweetened carbonated beverages (SSCB) and obesity in children and adolescents. One hundred seventy-four obese children with a similar number of sex and age-matched controls consumed a high amount of SSCB ( $>4$ servings/wk), and this was significantly associated with obesity $(p=0.01)$. Moreover, each additional daily serving of SSCB was associated with a $69 \%$ relative increase in the risk of obesity $(p=0.03)$, and there was a significant association between SSCB consumption and obesity risk. Our study showed that one hundred thirty-five (90\%) children and adolescents preferred to drink soft drinks, and the result in relation to the high BMI score and preference of soft drinks was significant ( $p=0.02, \mathrm{r}=0.141)$. However, some eating patterns that have been associated with unhealthy dietary behavior include eating while watching television [13] as our results showed. There was a significant correlation between eating in front of the television and the BMI SDS categories, and children and adolescents who ate in front of the television had a higher BMI SDS than those who did not eat in front of the television. Conversely, healthy dietary behaviors such as starting meals with salads had a significant association with the BMI scores; children who were not starting their meals with a salad had higher BMI scores than those who were starting their meals with a salad. 
Citation: Al-Agha AE, AL-Nosani NM (2016) Effect of the Family Food Environment and Dietary Behaviors on Obese Children and Adolescents. J Diabetes Metab 7: 661. doi:10.4172/2155-6156.1000661

Page 5 of 5

Sixty-one (29.6\%) of them were obese, and $52(25.2 \%)$ were severely obese. The findings according to Utter et al. [14] from 2008 suggest that the positive effect of family meals may reflect a positive home food environment. Consuming meals together as a family is associated with healthier food and supportive for eating healthier meals. We found that there was a negatively weak association between the BMI score and eating with family, thus this suggests that kids who eat with their family have lower BMI scores than kids who do not eat with their family. In addition, there was an association between the BMI score and eating regular meals, which was almost significant; thus, this suggests that children and adolescents who eat regular meals have a lower BMI score than kids who do not eat regular meals.

Increases in physical activity have a supporting role in preventing an increase in weight in children and adolescents $[15,16]$. Those who were not exercising for $30 \mathrm{~min}$ or more had a higher weight, whereas their height was controlled and they had a higher ratio score. Also, exercise for $30 \mathrm{~min}$ or more had a significant correlation with the ratio of center circumference to hip.

\section{Conclusions}

Obesity and overweight are increasing in KSA. Reducing overweight and obesity in children and adolescents is of considerable importance to public health. Therefore, we recommend implementing a national obesity prevention program at a community level to promote a leaner and consequently healthier community. Notably, the present study showed that exposure to poor-quality food environments has important effects on the eating patterns and obesity of children and adolescents in the same way that the availability of obesity-promoting foods such as fast food and soft drinks in the home along with unhealthy eating behaviors (e.g. eating in front of the television) increase the risk of obesity for both sexes.

In conclusion, we recommend a decrease in obesogenic dietary environments, e.g. eliminate fast food, make soft drinks less available at home, and avoid snacking and eating meals in front of the television. Moreover, there is an urgent need to spread awareness about children and adolescent obesity by using programs to promote a healthy family food environment and dietary behaviors. Our findings proved that there are a number of positive benefits for children and adolescents as a result of a home food environment, exercise for $\geq 30 \mathrm{~min}$, and the formality of eating meals (e.g. starting with vegetables and salads, and eating with family), including a lower risk of developing obesity. Thus, family-based interventions should be used to maintain awareness, and screenings for complications among obese children and adolescents are recommended to study the role of pre-diabetes and family history of diabetes mellitus in the outcome of general population is fundamental [15]. Finally, further comprehensive research is required to study the lifestyles of families of obese children, and determine how to prevent obesity and its complication in children and adolescents.

\section{Acknowledgements}

We are grateful for the essential cooperation and significant work that was performed by the statistical analyst, Mrs. Ghiras Jamil Softah. We sincerely appreciate her patience and effort since this study would not have been possible without her. We also thank all the participants and our volunteers.

\section{Disclaimer}

The authors have no conflict of interests, and the work was not supported or funded by any drug company. The work was not presented in any conference or club meeting.

\section{Reference}

1. Farghaly NF, Ghazali BM, AI-Wabel HM, Sadek AA, Abbag FI (2007) Life style and nutrition and their impact on health of Saudi school students in Abha Southwestern region of Saudi Arabia. Saudi Med J 28: 415-421.

2. Currie J, DellaVigna S, Moretti E, Pathania V (2009) The effect of fast food restaurants on obesity and weight gain. The National Bureau of Economic Research.

3. Al-Nozha MM, Al-Mazrou YY, Al-Maatouq MM, Arafah MR, Khalil MZ, et al (2005) Obesity in Saudi Arabia. Saudi Med J 26: 824-829.

4. Biro FM, Wien M (2010) Childhood obesity and adult morbidities. Am J Clin Nutr 9: 1499S-1505S.

5. Brisbois TD, Farmer AP, McCargar LJ (2012) Early markers of adult obesity: a review. Obes Rev 13: 347-367.

6. WHO-controlling the obesity epidemic (2004) International Obesity Task Force.

7. Mei Z, Grummer-Strawn LM, Pietrobelli A, Goulding A, Goran MI (2002) Validity of body mass index compared with other body-composition screening indexes for the assessment of body fatness in children and adolescents. Am J Clin Nutr 75: 7597-7985.

8. Daggett LM, Rigdon KL (2006) A computer-assisted instructional program for teaching portion size versus serving size. J Community Health Nurs 23: 29-35.

9. Mooreville M, Davey A, Orloski A, Hannah EL, Mathias KC, et al. (2015) Individual differences in susceptibility to large portion sizes among obese and normal-weight children. Obesity 23: 808-814.

10. Mashmoul M, Azlan A, Yusof B, Khaza ai H, Mohtarrudin N, et al. (2014) Effects of saffron extract and crocin on anthropometrical, nutritional and lipid profile parameters of rats fed a high fat diet. Journal of Functional Foods 8: 180-187.

11. Epstein LH, Saelens BE (2000) Behavioral economics of obesity: food intake and energy expenditure. Reframing Health Behavior Change with Behaviora Economics 2: 293-311.

12. Martin-Calvo N, Martínez-Gonzalez M, Bes-Rastrollo M, Gea A, Ochoa M, et al. (2014) Sugar-sweetened carbonated beverage consumption and childhood/ adolescent obesity: a case-control study. Public Health Nutr 17: 2185-2193.

13. Pearson N, Biddle SJ, Williams L, Worsley A, Crawford D, et al. (2014) Adolescent television viewing and unhealthy snack food consumption: the mediating role of home availability of unhealthy snack foods. Public Health Nutr 17: $317-323$

14. Utter J, Scragg R, Schaaf D, Mhurchu CN (2008) Relationships between frequency of family meals, BMI and nutritional aspects of the home food environment among New Zealand adolescents. Int $\mathrm{J}$ Behav Nutr Phys Act 5: 50 .

15. Murphy EC, Carson L, Neal W, Baylis C, Donley D, et al. (2009) Effects of an exercise intervention using Dance Dance Revolution on endothelial function and other risk factors in overweight children. Int J Pediatr Obes 4: 205-214

16. Ciccone MM, Scicchitano P, Cameli M, Cecere A, Cortese F, et al. (2014) Endothelial Function in Pre-diabetes, Diabetes and Diabetic Cardiomyopathy: A Review. J Diabetes Metab 5: 364. 